Check for updates

Cite this: RSC Adv., 2018, 8, 18560

\title{
Proton conductivity resulting from different triazole-based ligands in two new bifunctional decavanadates $\uparrow$
}

\author{
Jia-Peng Cao, $\$^{\mathrm{a}}$ Feng-Cui Shen, ${ }^{\mathrm{abc}}$ Xi-Ming Luo, ${ }^{\mathrm{a}}$ Chen-Hui Cui, ${ }^{\mathrm{a}}$ Ya-Qian Lan ${ }^{\star b}$ \\ and Yan Xu (D)*a
}

Triazole, similarly to imidazole, makes a prominent contribution to the proton conductivity of porous materials. To investigate the effects of triazole-based ligands in polyoxovanadates (POVs) on proton conduction, we designed and synthesized two decavanadate-based POVs, $\left[\mathrm{Zn}_{3}\left(\mathrm{C}_{2} \mathrm{H}_{4} \mathrm{~N}_{4}\right)_{6}\left(\mathrm{H}_{2} \mathrm{O}\right)_{6}\right]\left(\mathrm{V}_{10} \mathrm{O}_{28}\right)$. $14 \mathrm{H}_{2} \mathrm{O}$ (1) and $\left[\mathrm{Zn}_{3}\left(\mathrm{C}_{2} \mathrm{H}_{3} \mathrm{~N}_{3}\right)_{8}\left(\mathrm{H}_{2} \mathrm{O}\right)_{4}\right]\left(\mathrm{V}_{10} \mathrm{O}_{28}\right) \cdot 8 \mathrm{H}_{2} \mathrm{O}$ (2) constructed from the ligands 3-amino-1,2,4triazole and $1 \mathrm{H}-1,2,4$-triazole, respectively, via an aqueous solution evaporation method. Surprisingly, complex 1 obtained a superior proton conductivity of $1.24 \times 10^{-2} \mathrm{~S} \mathrm{~cm}^{-1}$ under $60{ }^{\circ} \mathrm{C}$ and $98 \% \mathrm{RH}$, which is much higher than that of complex 2. Furthermore, due to the contribution of the conjugate properties of the ligands to the third-order nonlinear optical (NLO) properties, we also studied its twophoton responses and achieved satisfactory results.

Received 28th March 2018

Accepted 30th April 2018

DOI: $10.1039 / \mathrm{c} 8 \mathrm{ra02694g}$

rsc.li/rsc-advances

performance of these materials has already been exploited to overcome the limitations of polymer membranes. ${ }^{5}$

As a category of significant metal-oxygen clusters composed A fuel cell (FC) is a power plant that converts the chemical energy present in fuels and oxidizers directly into electrical energy to provide alternative clean energy. ${ }^{1}$ In particular, proton exchange membrane fuel cells (PEMFCs) as the best option for transportation applications among fuel cells have drawn great interest from quite a few researchers. ${ }^{2}$ Currently, commercial Nafion membranes are the most common due to their superior proton conductivities of $10^{-1}-10^{-2} \mathrm{~S} \mathrm{~cm}^{-1}$ at $60-80^{\circ} \mathrm{C}$ with $98 \%$ relative humidity (RH). ${ }^{3}$ Nevertheless, Nafion membranes cannot retain their high conductivity at enhanced temperatures under comparatively low humidity, and also demand an intricate manufacturing process with high manufacturing costs. ${ }^{4}$ With the development of PEMFCs, there is an urgent need to design and synthesize new porous materials with versatile proton conductivity. Subsequently, due to the prominent chemical stability and low cost of inorganic and composite materials in manufacturing, the proton conductivity

${ }^{a}$ College of Chemical Engineering, State Key Laboratory of Materials-Oriented Chemical Engineering, Nanjing Tech University, Nanjing 210009, P. R. China. E-mail: yanxu@njtech.edu.cn

${ }^{b}$ Jiangsu Collaborative Innovation Centre of Biomedical Functional Materials, Jiangsu Key Laboratory of New Power Batteries, School of Chemistry and Materials Science, Nanjing Normal University, Nanjing 210023, P. R. China

${ }^{c}$ College of Biological and Chemical Engineering, Anhui Polytechnic University, Wuhu, 241000, P. R. China

$\dagger$ Electronic supplementary information (ESI) available. CCDC 1820884 and 1820885. For ESI and crystallographic data in CIF or other electronic format see DOI: $10.1039 / \mathrm{c} 8 \mathrm{ra} 02694 \mathrm{~g}$

$\$$ The authors contributed equally to this work. of transition metals, polyoxometalates (POMs) have aroused the interest of researchers in the field of proton conductivity ascribed to controlled structural design. As we know, in 1979, the first proton conductive material based on a POM was reported by Nakamura, and had high proton conductivities of 0.18 and $0.17 \mathrm{mho} \mathrm{cm}^{-1}\left(1 \mathrm{mho} \mathrm{cm}^{-1}=10^{-2} \mathrm{~S} \mathrm{~cm}^{-1}\right)$ at $25^{\circ} \mathrm{C}$ in the Keggin heteropoly compounds $\mathrm{H}_{3} \mathrm{PM}_{12} \mathrm{O}_{40} \cdot 29 \mathrm{H}_{2} \mathrm{O}(\mathrm{M}=\mathrm{Mo}$, W). ${ }^{6}$ Among the previously reported literature, the highest proton conductivity of $3.64 \times 10^{-2} \mathrm{~S} \mathrm{~cm}^{-1}$ was achieved in the Dawson structural POM $\mathrm{H}_{9} \mathrm{P}_{2} \mathrm{~W}_{15} \mathrm{~V}_{3} \mathrm{O}_{62} \cdot 28 \mathrm{H}_{2} \mathrm{O}$. In addition, hybrid POMs with triazole-based ligands have already been investigated, and exhibited predominant chemical stability and favourable proton conductivity properties. ${ }^{8}$ In 2015, Zheng's group reported the POM-based $\left[\mathrm{H}_{2} \mathrm{en}\right]_{4}\left[\mathrm{Ni}_{5}(\mathrm{OH})_{3}(\mathrm{~L})_{3}(\mathrm{en})\left(\mathrm{H}_{2^{-}}\right.\right.$ $\left.\mathrm{O})\left(\mathrm{B}-\alpha-\mathrm{PW}_{9} \mathrm{O}_{34}\right)\right] \cdot 6 \mathrm{H}_{2} \mathrm{O}$ (en = ethylenediamine) constructed via the introduction of a sulfurated triazole-based ligand $\left(\mathrm{L}=1 \mathrm{H}^{-}\right.$ 1,2,4-triazole-3-thiol $\left(\mathrm{H}_{2} \mathrm{trzS}\right)$ ). This material exhibited decent water stability and possessed a gratifyingly high yield, but had a relatively low proton conductivity value of $2.4 \times 10^{-4} \mathrm{~S} \mathrm{~cm}^{-1}$ at $85{ }^{\circ} \mathrm{C}$ and $98 \% \mathrm{RH}$, which has allowed for a very large development space. Thus, how to design and synthesize new protonconducting materials with different derivatives of functional species or groups such as triazoles to enhance proton conduction is a crucial objective. ${ }^{2 b}$

Recently, with the development of bifunctional and multifunctional materials, more and more researchers are concerned with bi- or multi-functionalized POM-based materials, with, for example, electrical, optical, magnetic and catalytic properties. ${ }^{9}$ 
Among the rest, electro-optical combination in POM-based functional materials with potential applications has received more attention. ${ }^{9 c}$ As a greatly important part of the optical properties, third-order nonlinear optical (NLO) properties were investigated for the reported POM-based inorganic-organic hybrid complexes, ${ }^{\mathbf{1 0}}$ from which it was undisputed that the conjugated units from organic ligands had a decisive contribution to the third-order NLO responses.

In this context, we designed and synthesized two decavanadate-based POVs on account of the contribution of triazole-based ligands to proton conductivity. Simultaneously, we selected different triazole-based ligands to compare their effects on the proton conductivity of the POVs. $\left[\mathrm{Zn}_{3}\left(\mathrm{C}_{2} \mathrm{H}_{4} \mathrm{~N}_{4}\right)_{6}\right.$ $\left.\left(\mathrm{H}_{2} \mathrm{O}\right)_{6}\right]\left(\mathrm{V}_{10} \mathrm{O}_{28}\right) \cdot 14 \mathrm{H}_{2} \mathrm{O}(\mathrm{1})$ and $\left[\mathrm{Zn}_{3}\left(\mathrm{C}_{2} \mathrm{H}_{3} \mathrm{~N}_{3}\right)_{8}\left(\mathrm{H}_{2} \mathrm{O}\right)_{4}\right]\left(\mathrm{V}_{10} \mathrm{O}_{28}\right) \cdot$ $8 \mathrm{H}_{2} \mathrm{O}$ (2) were successfully synthesized with 3-amino-1,2,4triazole and $1 H$-1,2,4-triazole, respectively, via an aqueous solution evaporation method, and were then structurally characterized. A proton conductivity of $1.24 \times 10^{-2} \mathrm{~S} \mathrm{~cm}^{-1}$ at $60^{\circ} \mathrm{C}$ with 98\% RH for complex 1, was obtained using proton conductivity measurements and analyses. Due to the higher number of lattice water molecules moving in a disordered way in $\mathbf{1}$, the proton conductivity of $\mathbf{1}$ is much higher than that of complex 2, which could be explained with the Grotthuss mechanism. ${ }^{2 b}$ More than that, the main effect is that the 3-amino-1,2,4-triazole of 1 has a more protonated $-\mathrm{NH}_{2}$ than the $1 \mathrm{H}-1,2,4$-triazole of 2 , which is ascribed to the vehicle mechanism. ${ }^{15}$ That is to say, the proton conductivities of the two complexes combined two mechanisms, the Grotthuss mechanism and a partial vehicle mechanism. Furthermore, since the N-miscellaneous triazole five-membered ring formed a conjugate unit, an important factor that leads to a third-order NLO response, we also made a thorough inquiry into the third-order NLO properties of the two compounds and obtained satisfactory results.

\section{Experimental section}

\section{Materials and general methods}

A simple and fascinating synthetic method was used in this article. All of the reagents that we used were purchased from Sinopharm and were not further purified. In addition, elemental analyses of $\mathrm{C}, \mathrm{H}$, and $\mathrm{N}$ were obtained using a PerkinElmer 2400 elemental analyzer. $\mathrm{KBr}$ pellets with the samples were used to record FT-IR spectra on a Nicolet Impact 410 Fourier transform infrared spectrometer in a range of 4000 to $400 \mathrm{~cm}^{-1}$. Moreover, the data of the powder XRD patterns collected at $2 \theta$ from $5^{\circ}$ to $50^{\circ}$ were acquired on a Bruker D8X diffractometer faultlessly fitted out with monochromatized $\mathrm{Cu}$ $\mathrm{K} \alpha(\lambda=0.15418 \mathrm{~nm})$ radiation at room temperature. TGA measurements were carried out on a Diamond thermogravimetric analyzer in a floating $\mathrm{N}_{2}$ atmosphere with a measurement interval from 25 to $800{ }^{\circ} \mathrm{C}$ accompanied by a heating rate of $10{ }^{\circ} \mathrm{C} \mathrm{min}^{-1}$.

\section{Synthesis of $\left[\mathrm{Zn}_{3}\left(\mathrm{C}_{2} \mathrm{H}_{4} \mathrm{~N}_{4}\right)_{6}\left(\mathrm{H}_{2} \mathrm{O}\right)_{6}\right]\left(\mathrm{V}_{10} \mathrm{O}_{28}\right) \cdot 14 \mathrm{H}_{2} \mathrm{O}$ (1)}

A mixture of $\mathrm{V}_{2} \mathrm{O}_{5}(0.1505 \mathrm{~g}, 0.8 \mathrm{mmol}), \mathrm{ZnSO}_{4} \cdot 7 \mathrm{H}_{2} \mathrm{O}(0.1498 \mathrm{~g}$, $0.5 \mathrm{mmol}), 3$-amino-1,2,4-triazole $(0.0518 \mathrm{~g}, 0.6 \mathrm{mmol})$ and
$\mathrm{LiOH}(0.0603 \mathrm{~g}, 1.5 \mathrm{mmol})$ was added to $8 \mathrm{~mL}$ of distilled water and stirred for approximately $3 \mathrm{~h}$ at room temperature. After stirring well, $2 \mathrm{M}$ acetic acid solution was added to adjust the mixture to about $\mathrm{pH}=4$. After a few minutes, the insoluble precipitate was removed via filtration and the clear solution was evaporated at room temperature. Four days later, orange/yellow block crystals were obtained. Yield: $36 \%$ (based on V). Elemental analysis calcd (found\%) for the complex: calcd for $\mathrm{C}$, 7.14; H, 3.17; N, 16.65; found for C, 7.24; H, 3.31; N, 16.71.

\section{Synthesis of $\left[\mathrm{Zn}_{3}\left(\mathrm{C}_{2} \mathrm{H}_{3} \mathrm{~N}_{3}\right)_{8}\left(\mathrm{H}_{2} \mathrm{O}\right)_{4}\right]\left(\mathrm{V}_{10} \mathrm{O}_{28}\right) \cdot 8 \mathrm{H}_{2} \mathrm{O}$ (2)}

The synthetic procedure for compound 2 was similar to that of 1, except that $1 \mathrm{H}-1,2,4$-triazole $(0.0520 \mathrm{~g}, 0.6 \mathrm{mmol})$ was used to substitute for 3-amino-1,2,4-triazole. Besides this, the evaporation time of complex 2 was much shorter than that of $\mathbf{1}$. Only one day later, orange/yellow block crystals were obtained. Yield: $44 \%$ (based on $\mathrm{V}$ ). Elemental analysis calcd (found\%) for the complex: calcd for C, 9.99; H, 2.50; N, 17.48; found for C, 10.12; H, 2.59; N, 17.53.

\section{X-ray crystallography}

X-ray analysis data for $\mathbf{1}$ and $\mathbf{2}$ were obtained on a Bruker Apex II CCD diffractometer at $296 \mathrm{~K}$, with graphite monochromatized Mo-K $\alpha$ radiation $(\lambda=0.71073 \AA)$. The structures were solved using direct methods and refined via full-matrix least-squares using the SHELXL-2014 crystallographic software package. The non-hydrogen atoms were refined anisotropically. During the refinement, the thermal parameters of water and some of the $\mathrm{C}$ atoms were restrained. CCDC 1820884 and 1820885. $\dagger$ All the crystallographic information for $\mathbf{1}$ and $\mathbf{2}$ is listed in Table 1.

\section{Results and discussion}

\section{Synthesis}

Over the past few years, the hydrothermal method has been proven to be a cogent approach for the preparation of polyoxovanadates. During a conventional hydrothermal method, numerous factors can impact the nucleation and crystal development of the final products, for example, the initial reactant, the reactant concentration, the solvents, the reaction time, the $\mathrm{pH}$ values, and the reaction temperature. However, it is worth noting that we used the volatilization method of adjusting the $\mathrm{pH}$ value without heating. The experimental PXRD patterns of the bulk products of compounds $\mathbf{1}$ and $\mathbf{2}$ are consistent with the simulated ones calculated from X-ray single-crystal diffraction (Fig. S6 and S7†), which indicates the phase purity of the two compounds. The intensity difference between the experimental and simulated PXRD patterns may be ascribed to the variation in the preferred orientation of the powder sample during measurements. The thermal analysis and IR spectra of both compounds are shown in Fig. S9-S11. $\dagger$

\section{Analysis of crystal structures}

The crystal structure of compounds 1 and 2 . Single-crystal Xray diffraction analysis reveals that $\mathbf{1}$ and $\mathbf{2}$ both crystallized in the triclinic space group $P \overline{1}$. The molecular structure of complex 
Table 1 Crystal data and structure refinements for compounds 1 and 2

\begin{tabular}{|c|c|c|}
\hline Compound & 1 & 2 \\
\hline Formula & $\mathrm{C}_{12} \mathrm{H}_{64} \mathrm{~N}_{24} \mathrm{O}_{48} \mathrm{~V}_{10} \mathrm{Zn}_{3}$ & $\mathrm{C}_{16} \mathrm{H}_{48} \mathrm{~N}_{24} \mathrm{O}_{40} \mathrm{~V}_{10} \mathrm{Zn}_{3}$ \\
\hline Formula weight & 2018.38 & 1922.29 \\
\hline Crystal system & Triclinic & Triclinic \\
\hline Space group & $P \overline{1}$ & $P \overline{1}$ \\
\hline$a(\AA)$ & 11.53(3) & $10.775(13)$ \\
\hline$\alpha(\mathrm{deg})$ & $96.31(3)$ & $117.801(12)$ \\
\hline$\beta$ (deg) & $110.35(3)$ & $94.002(15)$ \\
\hline$\gamma(\mathrm{deg})$ & $96.93(4)$ & $103.534(13)$ \\
\hline$V\left(\AA^{3}\right)$ & $1624(8)$ & $1490(3)$ \\
\hline$Z$ & 1 & 1 \\
\hline$D_{\mathrm{c}}\left(\mathrm{g} \mathrm{m}^{-3}\right)$ & 2.064 & 2.142 \\
\hline Reflections collected/unique & $11245 / 5608$ & $10455 / 5292$ \\
\hline$R$ (int) & 0.0870 & 0.0542 \\
\hline Data/restraints/parameters & $5553 / 74 / 492$ & $5292 / 48 / 427$ \\
\hline GOF & 1.039 & 1.076 \\
\hline$R_{1}^{a}, \mathrm{w}_{2}{ }^{b}[I>2 \sigma(I)]$ & $0.0773,0.1561$ & $0.0475,0.1273$ \\
\hline$R_{1}$, w $R_{2}$ (all data) & $0.1542,0.1780$ & $0.0690,0.1382$ \\
\hline
\end{tabular}

1 consists of isolated $\left[\mathrm{V}_{10} \mathrm{O}_{28}\right]$ cluster anions, $\left[\mathrm{Zn}_{3}\left(\mathrm{C}_{2} \mathrm{H}_{4} \mathrm{~N}_{4}\right)_{6}\right.$ $\left.\left(\mathrm{H}_{2} \mathrm{O}\right)_{6}\right]$ coordination cations, and hydration water molecules found among the intervals of the polyanions and cations, as shown in Fig. 1a and b. Compared with $\mathbf{1}$, the isolated $\left[\mathrm{Zn}_{3}\right.$ $\left.\left(\mathrm{C}_{2} \mathrm{H}_{3} \mathrm{~N}_{3}\right)_{8}\left(\mathrm{H}_{2} \mathrm{O}\right)_{4}\right]$ cluster cations are found to be dissimilar in complex 2. A typical $\left[\mathrm{V}_{10} \mathrm{O}_{28}\right]$ cluster consists of ten edge-sharing $\left[\mathrm{VO}_{6}\right]$ octahedra (Fig. S1a $\dagger$ ), and the $\mathrm{V}-\mathrm{O}$ bond distances vary
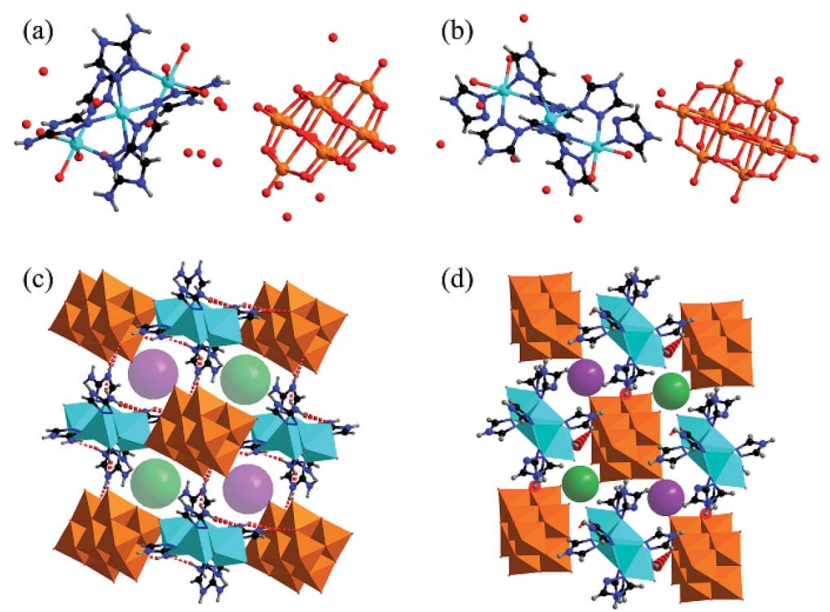

Fig. 1 The asymmetric building blocks of complex 1 (a) and complex 2 (b). V: orange; Zn: turquoise; C: black; N: blue; O: red and H: gray. The three-dimensional supramolecular structures of complex 1 (c) and complex 2 (d) connected by hydrogen bonds. The free water molecules were omitted for clarity (violet and green: the sizes of the channels in 1 and 2, found to be $8.58 \AA$ and $3.66 \AA$, respectively). from $1.610(8)$ to $2.302(8) \AA$, which are similar to those of the reported decavanadate structure. ${ }^{11}$ There are two crystallographically independent $\mathrm{Zn}$ ions (Zn1 and Zn2) in compound 1. $\mathrm{Zn} 2$ is six-coordinated by three $\mathrm{N}$ atoms from the ligands and three $\mathrm{O}$ atoms from the water molecules. $\mathrm{Zn} 1$ is located at a symmetry center $(1.5,1.5,0)$, bonded by six $\mathrm{N}$ atoms from different ligands, and connects two octahedral $\mathrm{ZnN}_{3} \mathrm{O}_{3}(\mathrm{Zn} 2)$ to form a $\left[\mathrm{Zn}_{3}\left(\mathrm{C}_{2} \mathrm{H}_{4} \mathrm{~N}_{4}\right)_{6}\left(\mathrm{H}_{2} \mathrm{O}\right)_{6}\right]$ coordination cation as shown in Fig. S1b. $\uparrow$ The bond lengths of $\mathrm{Zn}-\mathrm{N}$ and $\mathrm{Zn}-\mathrm{O}$ range from 2.086(11) to 2.205(9) $\AA$ and from 2.133(9) to 2.207(9) $\AA$, respectively. These are comparable with the reported values of the $\mathrm{Zn}$ compounds. ${ }^{11}$

The $\mathrm{V}_{10} \mathrm{O}_{28}$ polyanions and $\mathrm{Zn}_{3}$ coordination cations in complexes $\mathbf{1}$ and $\mathbf{2}$ are connected to each other by the hydrogen bonds of $\mathrm{N}-\mathrm{H} \cdots \mathrm{O}$ (Table $\mathrm{S} 5$ and $\mathrm{S} 6 \dagger$ ) to form three-dimensional supramolecular structures, as shown in Fig. S3a and S4a. $\uparrow$ The $\mathrm{N} \cdots \mathrm{O}$ distances in $\mathbf{1}$ vary from $2.771(14)$ to $3.083(14) \AA$. In the structure of complex 1 , each $\left[\mathrm{V}_{10} \mathrm{O}_{28}\right]$ cluster anion is surrounded by six $\left[\mathrm{Zn}_{3}\left(\mathrm{C}_{2} \mathrm{~N}_{4} \mathrm{H}_{4}\right)_{6}\left(\mathrm{H}_{2} \mathrm{O}\right)_{6}\right]^{6+}$ cations connected by hydrogen bonds, which generates soft channels (Fig. S3b $\dagger$ ).

Nevertheless, because of the smaller steric hindrance of $1 H^{-}$ 1,2,4-triazole than 3-amino-1,2,4-triazole, in the 3D supramolecular structure of complex 2, each $\left[\mathrm{V}_{10} \mathrm{O}_{28}\right]$ cluster anion connects eight $\left[\mathrm{Zn}_{3}\left(\mathrm{C}_{2} \mathrm{~N}_{3} \mathrm{H}_{3}\right)_{8}\left(\mathrm{H}_{2} \mathrm{O}\right)_{4}\right]$ units using hydrogen bonds (Fig. S4 $\mathrm{b} \dagger$ ). Hence, the three-dimensional pores of complex $\mathbf{1}$ are much larger than those of complex 2. As shown in Fig. $1 \mathrm{c}$ and d, the sizes of the channels in $\mathbf{1}$ and $\mathbf{2}$ are about $8.6 \AA$ and $3.7 \AA$, respectively. The above channels in both compounds provide the path for the proton propagation. 
Proton conductivity. The proton conductivities of complexes 1 and 2 were investigated using alternating current (AC) impedance spectroscopy at diverse temperatures and various levels of humidity. To demonstrate the relation between conductivity and relative humidity $(\mathrm{RH})$, we obtained the conductivities of complexes $\mathbf{1}$ and 2 at $30{ }^{\circ} \mathrm{C}$ under various humidity conditions (Fig. 2a and c). At $40 \% \mathrm{RH}$, the conductivity of complex 1 was considered to be an almost inappreciable value of $1.57 \times 10^{-9} \mathrm{~S} \mathrm{~cm}^{-1}$. Subsequently, the conductivity value of complex 1 gradually increases to $1.08 \times 10^{-3} \mathrm{~S} \mathrm{~cm}^{-1}$ with the increase of humidity to $80 \% \mathrm{RH}$. Then, the conductivity value of complex 1 slowly increases with increasing $\mathrm{RH}$ in a narrow range of high $\mathrm{RH}$ until it reaches $2.67 \times 10^{-3} \mathrm{~S} \mathrm{~cm}^{-1}$ at $98 \%$ RH. However, the value of proton conductivity for complex 2 is only $9.85 \times 10^{-5} \mathrm{~S} \mathrm{~cm}^{-1}$ at $98 \% \mathrm{RH}$, which is much lower than that for 1 . The increase in proton conductivity with the increase in $\mathrm{RH}$ shows that the proton-conducting behavior in the complex is typically controlled by water-mediated proton conduction. $^{\mathbf{1 2}}$

Simultaneously, the proton conductivities of complexes 1 and 2 were also obtained in the temperature range $30-60{ }^{\circ} \mathrm{C}$ (Fig. 2b and d) with $5{ }^{\circ} \mathrm{C}$ intervals. Finally, the optimal proton conductivities of complexes 1 and 2 were determined to be decent values of $1.24 \times 10^{-2} \mathrm{~S} \mathrm{~cm}^{-1}$ and $4.29 \times 10^{-4} \mathrm{~S} \mathrm{~cm}^{-1}$, respectively, under $60{ }^{\circ} \mathrm{C}$ and $98 \% \mathrm{RH}$. What's more, multiple repetitive tests indicated that the value of the proton conductivity for compounds 1 and 2 could stabilize at $10^{-2}$ and $10^{-4}$, respectively. The stability of both compounds after the impedance measurements is shown in Fig. S7 and S8. $\dagger$ For compound 1, we tested the impedance several times and found that its proton conductivity was between $10^{-1} \mathrm{~S} \mathrm{~cm}^{-1}$ and $10^{-2} \mathrm{~S} \mathrm{~cm}^{-1}$, and that the highest value it could reach was $1.25 \times$ $10^{-1} \mathrm{~S} \mathrm{~cm}^{-1}$. However, we chose a more stable value of $1.24 \times$ $10^{-2} \mathrm{~S} \mathrm{~cm}^{-1}$ for reporting. For compound 2, we tested the impedance several times and found that its proton conductivity was between $10^{-4} \mathrm{~S} \mathrm{~cm}^{-1}$ and $10^{-5} \mathrm{~S} \mathrm{~cm}^{-1}$. We chose a more stable value of $4.26 \times 10^{-4} \mathrm{~S} \mathrm{~cm}^{-1}$ for reporting.

Moreover, we fitted the slope with least-squares to obtain the activation energy of the complex and to enhance our insights into the proton conduction mechanism (Fig. 3). At 98\% relative humidity, the energy of activation $\left(E_{\mathrm{a}}\right)$ of complex 1 is $0.53 \mathrm{eV}$ and of complex 2 is $0.58 \mathrm{eV}$. To explain proton conduction, two cardinal mechanisms (the Grotthuss mechanism and the vehicle mechanism) were used, ${ }^{13}$ as these have a strong
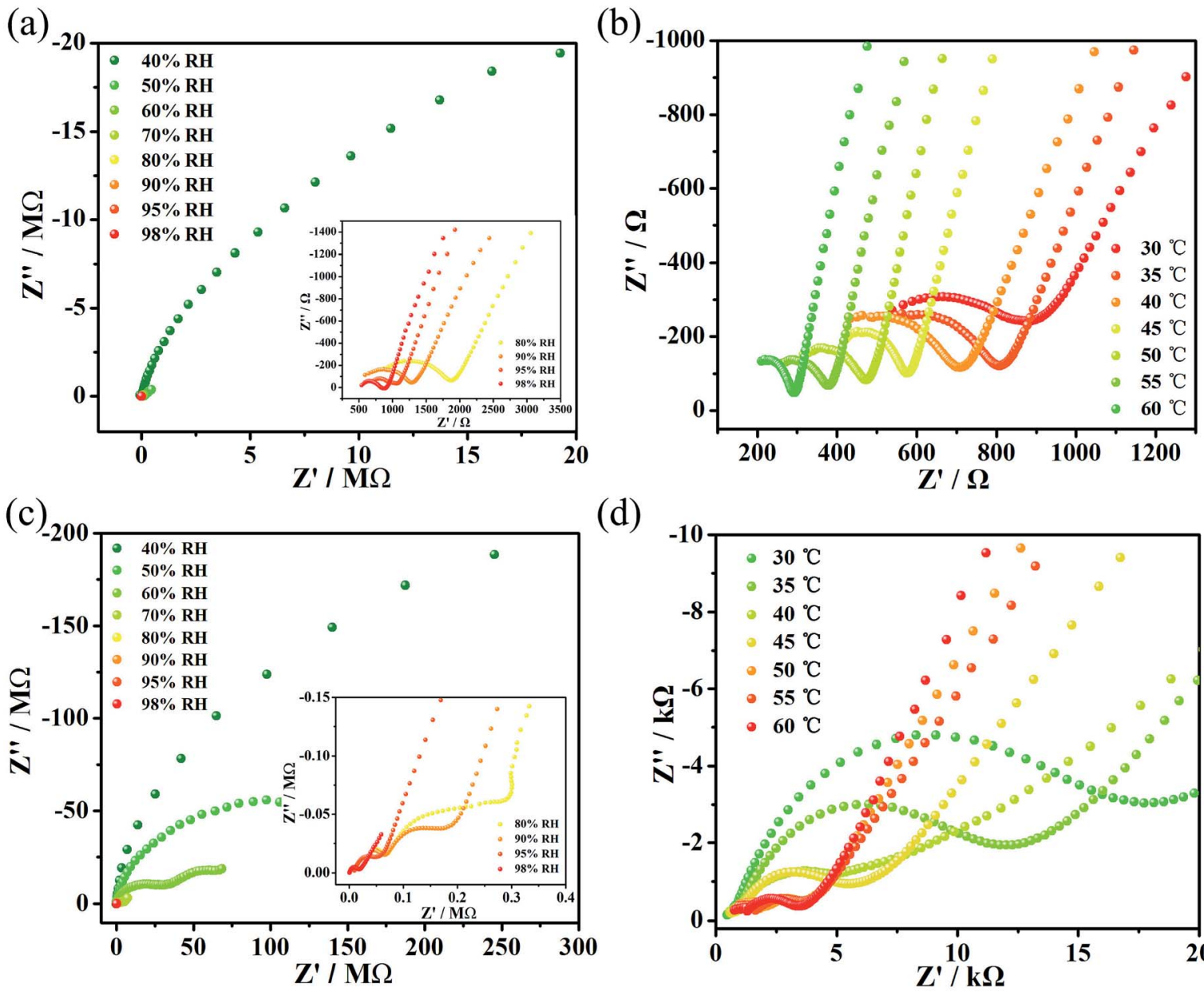

(d)

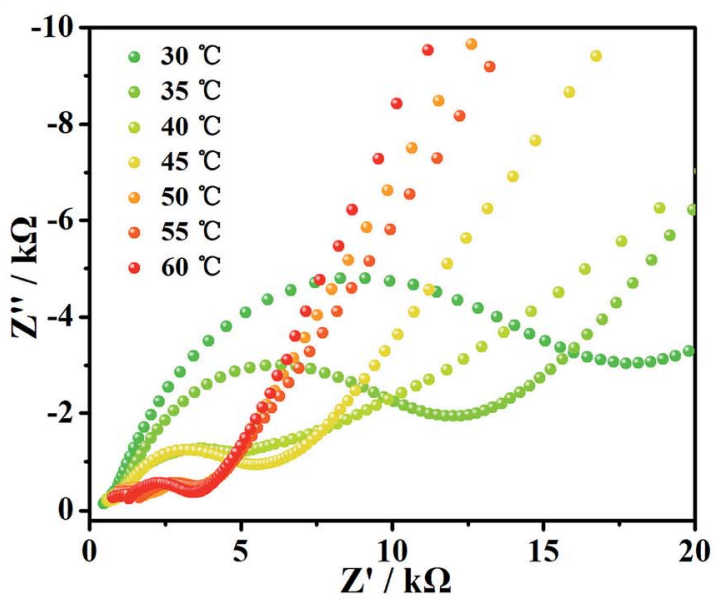

Fig. 2 (a) Impedance spectrum of complex 1 under different $\mathrm{RH}$ conditions at $30{ }^{\circ} \mathrm{C}$. (b) Impedance spectrum of complex 1 at different temperatures at $98 \% \mathrm{RH}$. (c) Impedance spectrum of complex 2 under different $\mathrm{RH}$ conditions at $30^{\circ} \mathrm{C}$. (d) Impedance spectrum of complex 2 at different temperatures at $98 \% \mathrm{RH}$. 
association with proton transport. The Grotthuss mechanism establishes the paths for proton conductivity via an infinite soft hydrogen bond network and the vehicle mechanism will be considered as only a model that is mainly caused by the movement of protons usually accompanied by the auxiliary movement of a vehicle $\left(\right.$ e.g. $\left., \mathrm{H}_{2} \mathrm{O}, \mathrm{NH}_{3}\right)$. Due to the above characteristics, the two mechanisms can be distinguished via the magnitude of the activation energies. ${ }^{4 a}$ Typically, in the Grotthuss mechanism, the activation energies are in a range of 0.1 to $0.4 \mathrm{eV}$ and correspondingly, the vehicle mechanism can be ascertained from an $E_{\mathrm{a}}$ of 0.5 to $0.9 \mathrm{eV},{ }^{\mathbf{1 4}}$ which suggests that the vehicle mechanism may exist in these two complexes.

According to the structural and activation energy analysis of the two compounds, further insight into the proton channels and mechanisms can be gained from cole-cole fitting (as shown in Fig. $\mathrm{S} 12 \dagger)$. In complex $\mathbf{1}$, the $\mathrm{V}-\mathrm{O}$ cluster anions and the $\left[\mathrm{Zn}_{3}\left(\mathrm{C}_{2} \mathrm{~N}_{4} \mathrm{H}_{4}\right)_{6}\left(\mathrm{H}_{2} \mathrm{O}\right)_{6}\right]^{6+}$ cations were connected by hydrogen bonds to form 3D supramolecular structures (Fig. 4) with narrow channels and a large amount of water moving in a disorderly way in these channels, facilitating proton conduction and thus resulting in a lower activation energy, which is attached to the Grotthuss mechanism. What's more, six coordinated 3-amino-1,2,4-triazole could contribute abundant protons to the weak $\mathrm{N}-\mathrm{H}$ bonds, resulting in a high activation energy and a partial vehicle mechanism. That is to say, the proton conductivity of complex 1 combined two mechanisms, the Grotthuss mechanism and a partial vehicle mechanism. ${ }^{2 b, 15}$ Compared to complex 1, although two more coordinated $1 H^{-}$ 1,2,4-triazoles superseded the two coordinated water molecules in 2 , the $-\mathrm{NH}_{2}$ of each 3-amino-1,2,4-triazole can provide more plentiful protons. Furthermore, the hydration water molecules in complex 1 are more abundant. At the same time, the size of the pores will directly affect the proton propagation within them, thus further affecting the proton conductivity, and the size of the channels in complex 1 is about $8.6 \AA$, which is larger than the $3.66 \AA$ channels in complex 2. Hence, the proton conductivity of complex $2\left(4.29 \times 10^{-4} \mathrm{~S} \mathrm{~cm}^{-1}\right)$ is far less than that of complex $1\left(1.24 \times 10^{-2} \mathrm{~S} \mathrm{~cm}^{-1}\right)$.

Third-order NLO properties. Since complexes $\mathbf{1}$ and $\mathbf{2}$ have triazole-based organic ligands with conjugate units that are

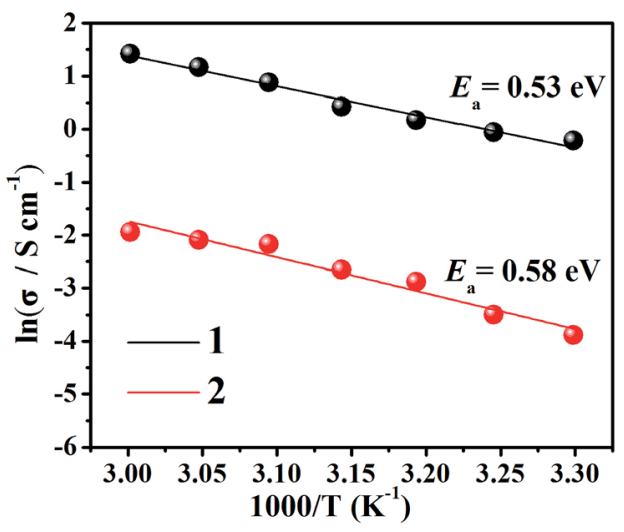

Fig. 3 Arrhenius plots of proton conductivity for complexes 1 (black) and 2 (red) under $98 \% \mathrm{RH}$ conditions.

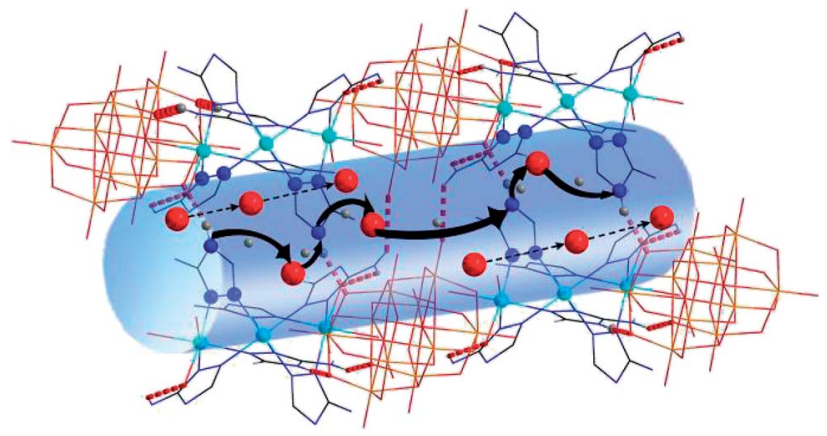

Fig. 4 Schematic view of the possible proton-conductive pathways in complex 1. Water molecules are shown in red. The nitrogen atoms of the ligands are shown in blue. The hydrogen atoms of the ligands are shown in gray. The black arrows show the protons hopping along hydrogen bonding networks formed by the coordinated triazolebased ligands and the lattice water. The black dotted arrows represent the transport of protons through the self-diffusion of the protonated water.

decisive for third-order NLO responses, we investigated the solute third-order NLO properties of the two compounds. To measure the third-order NLO responses and two-photon absorption cross sections $(\sigma)$ of compounds 1 and 2, the progressive open-aperture Z-scan technique was adopted. A sample of complex $\mathbf{1}$ was dissolved in aqueous solution at a concentration of 10-4 mol L ${ }^{-1}$ and measured under a laser beam with a wavelength of $720 \mathrm{~nm}$. However, the sample of complex 2 was dissolved in a solution of DMSO at a concentration of 10-4 mol L ${ }^{-1}$ and measured under a laser beam with a wavelength of $700 \mathrm{~nm}$. As shown in Fig. 5, complexes 1 and 2 were measured using the typical Z-scan method. The experimental data are represented by filled black squares, which can be fitted using the theoretical simulated red light based on the following equations: ${ }^{16}$

$$
\begin{gathered}
T(z, s=1)=\sum_{m=0}^{\infty} \frac{\left[-q_{0}(z)\right]^{m}}{(m+1)^{3 / 2}} \\
q_{0}(z)=\frac{\beta I_{0} L_{\mathrm{eff}}}{1+x^{2}}
\end{gathered}
$$

where $I_{0}$ is the input intensity, which can be calculated at the focus of $z=0$ and acquired after dividing the input energy by $\pi \omega_{0}{ }^{2} . L_{\text {eff }}$ is the effective length, in which $L$ represents the sample length and $\alpha$ represents the linear absorption coefficient. In the denominator of eqn (2), $x=z / z_{0}$, where $z$ stands for the sample position. $z_{0}=\pi \omega_{0}{ }^{2} / \lambda$ denotes the diffraction length of the laser beam, in which $\omega_{0}$ is the spot size at the place of focus, and $\lambda$ is the wavelength of the beam. Besides this, we obtained the NL absorption coefficient $\beta$ using the aforementioned equations. The two-photon absorption cross section $\sigma$ can be calculated using the following evaluation:

$$
\sigma=h \nu \beta / N_{\mathrm{A}} d \times 10^{-3}
$$

where $h \nu$ is the energy of the incident illumination, $N_{\mathrm{A}}$ represents Avogadro's constant, and $d$ is the concentration of the complex. By computation, the values of $\beta$ for compounds $\mathbf{1}$ and 
(a)

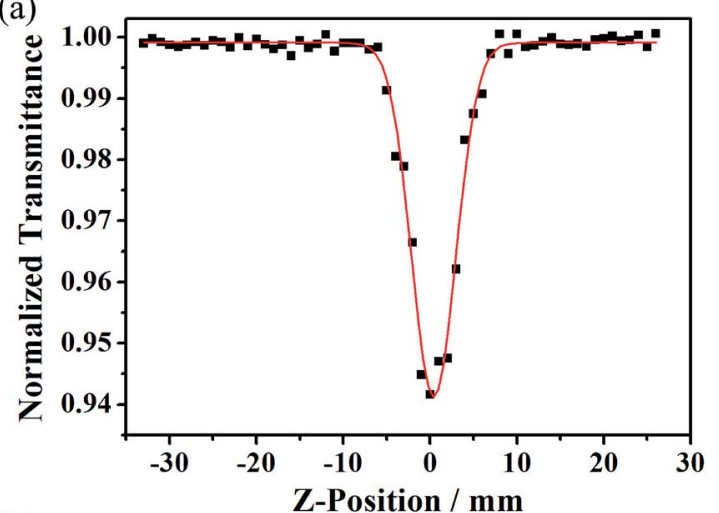

(b)

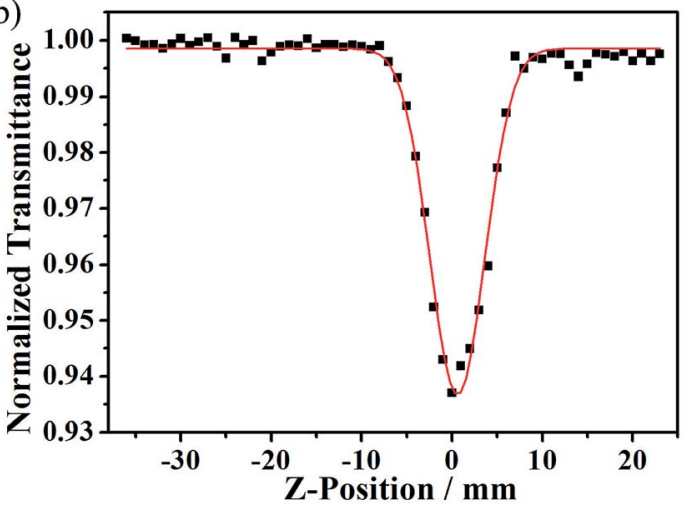

Fig. 5 The Z-scan data of 1 in aqueous solution (a) and of 2 in DMSO solution (b), which were acquired under an open-aperture Z-scan. The black squares represent the experimental data, and the red curves were fitted using the theoretical equations.

2 are $0.006767 \mathrm{~cm} \mathrm{GW}^{-1}$ and $0.004494 \mathrm{~cm} \mathrm{GW}^{-1}$, respectively, and the values of $\sigma$ for compounds 1 and 2 are $3102.13 \mathrm{GM}$ and 2118.82 GM ( $1 \mathrm{GM}=10^{-50} \mathrm{~cm}^{4} \mathrm{~s}$ per photon), respectively.

\section{Conclusions}

In summary, to investigate the effects of different triazole-based ligands on proton conduction, we successfully prepared two isolated decavanadate-based bifunctional POVs, $\left[\mathrm{Zn}_{3}\left(\mathrm{C}_{2} \mathrm{H}_{4}\right.\right.$ $\left.\left.\mathrm{N}_{4}\right)_{6}\left(\mathrm{H}_{2} \mathrm{O}\right)_{6}\right]\left(\mathrm{V}_{10} \mathrm{O}_{28}\right) \cdot 14 \mathrm{H}_{2} \mathrm{O}$ and $\left[\mathrm{Zn}_{3}\left(\mathrm{C}_{2} \mathrm{H}_{3} \mathrm{~N}_{3}\right)_{8}\left(\mathrm{H}_{2} \mathrm{O}\right)_{4}\right]\left(\mathrm{V}_{10} \mathrm{O}_{28}\right)$. $8 \mathrm{H}_{2} \mathrm{O}$. The proton conductivity of complex 1 is much higher than that of complex 2 under the same conditions due to the greater number of lattice water molecules and the protonated $-\mathrm{NH}_{2}$ of 3-amino-1,2,4-triazole. The outcome of this work contributes to the understanding of how proton conduction is affected by different triazole-based ligands and will benefit the further investigation of new POV-based proton-conduction materials. Further studies will be focused on the preparation of large single crystals, and the proton conductivity of single crystals with anisotropic characterization along and perpendicular to the channels.

\section{Conflicts of interest}

There are no conflicts to declare.

\section{Acknowledgements}

This work was supported by the Natural Science Foundation of China (Grant 21571103) and the Major Natural Science Projects of the Jiangsu Higher Education Institution (Grant 16KJA150005).

\section{References}

1 S. Hamrock and M. Yandrasits, Polym. Rev., 2006, 46, 219. 2 (a) M.-Z. Jacobson, W.-G. Colella and D.-M. Golden, Science, 2005, 308, 1901; (b) F.-M. Zhang, L.-Z. Dong, J.-S. Qin, W. Guan, J. Liu, S.-L. Li, M. Lu, Y.-Q. Lan, Z.-M. Su and H.-C. Zhou, J. Am. Chem. Soc., 2017, 139, 6183; (c) Y.-X. Ye, W.-G. Guo, L.-H. Wang, Z.-Y. Li, Z.-J. Song, J. Chen, Z.-J. Zhang, S.-C. Xiang and B.-L. Chen, J. Am. Chem. Soc., 2017, 139, 15604; (d) B. Li, H.-M. Wen, Y.-J. Cui, W. Zhou, G.-D. Qian and B. Chen, Adv. Mater., 2016, 28, 8819.

3 (a) C. Laberty-Robert, K. Valle, F. Pereira and C. Sanchez, Chem. Soc. Rev., 2011, 40, 961; (b) K.-A. Mauritz and R.-B. Moore, Chem. Rev., 2004, 104, 4535; (c) Q. Li, R. He, J.-O. Jensen and N.-J. Bjerrum, Chem. Mater., 2003, 15, 4896. 4 (a) X. Meng, H.-N. Wang, S.-Y. Song and H.-J. Zhang, Chem. Soc. Rev., 2017, 46, 464; (b) M. Yoon, K. Suh, P.-S. Natarajan and P.-K. Kim, Angew. Chem., Int. Ed., 2013, 125, 2752; (c) B. Dong, L. Gwee, D. Salas-de la Cruz, K.-I. Winey and Y.-A. Elabd, Nano Lett., 2010, 10, 3785.

5 (a) X. Liang, F. Zhang, W. Feng, X. Zou, C. Zhao, H. Na, C. Liu, F. Sun and G. Zhu, Chem. Sci., 2013, 4, 983; (b) H.-S. Thiam, W.-R.-W. Daud, S.-K. Kamarudin, A.-B. Mohammad, A.-A.-H. Kadhum, K.-S. Loh and E.-H. Majlan, Int. J. Hydrogen Energy, 2011, 36, 3187; (c) C. Laberty-Robert, K. Vallé, F. Pereira and C. Sanchez, Chem. Soc. Rev., 2011, 40, 961; (d) W.-F. Chen, J.-S. Wu and P.-L. Kuo, Chem. Mater., 2008, 20, 5756; (e) T. Tezuka, K. Tadanaga, A. Hayashi and M. Tatsumisago, J. Am. Chem. Soc., 2006, 128, 16470; (f) G.-L. Athens, Y. Ein-Eli and B.-F. Chmelka, Adv. Mater., 2007, 19, 2580; $(g)$ B. Lin, S. Cheng, L. Qiu, F. Yan, S. Shang and J. Lu, Chem. Mater., 2010, 22, 1807; (h) C. Dey, T. Kundu and R. Banerjee, Chem. Commun., 2012, 48, 266.

6 O. Nakamura, T. Kodama, I. Ogino and Y. Miyake, Chem. Lett., 1979, 1, 17.

7 X. Tong, X. Wu, Q. Wu, W. Zhu, F. Cao and W. Yan, Dalton Trans., 2012, 41, 9893.

8 G.-J. Cao, J.-D. Liu, T.-T. Zhuang, X.-H. Cai and S.-T. Zheng, Chem. Commun., 2015, 51, 2048.

9 (a) J. Long, J. Rouquette, J.-M. Thibaud, R.-A.-S. Ferreira, L.-D. Carlos, B. Donnadieu, V. Vieru, L.-F. Chibotaru, L. Konczewicz, J. Haines, Y. Guari and J. Larionova, Angew. Chem., Int. Ed., 2015, 54, 2236; (b) M.-J. Liu, J. Yuan, Y.-Q. Zhang, H.-L. Sun, C.-M. Liu and H.-Z. Kou, Dalton Trans., 2017, 46, 13035; (c) Y.-L. Zhai, Z.-J. Zhu, C.-Z. Zhu, J.-B. Zhu, J.-T. Ren, E. Wanga and S.-J. Dong, Nanoscale, 2013, 5, 4344; (d) J.-M. Caballero, A.-S.-J. Wery, S. Reinoso, B. Artetxe, L.-S. Felices, B.-E. Bakkali, G. Trautwein, J.-A. Monge, J.-L. Vilas and J. M.-G. Zorrilla, Inorg. Chem., 2016, 55, 4970; (e) M. Amini, M. Nikkhoo, 
S.-B. Tekantappeh, S. M. F. Farnia, G. Mahmoudi and O. Büyükgüngör, Inorg. Chem. Commun., 2017, 77, 72.

10 (a) J.-Y. Niu, X.-Z. You, C.-Y. Duan, H.-K. Fun and Z.-Y. Zhou, Inorg. Chem., 1996, 35, 4211; (b) F.-Q. Liu, L. Wang, J.-X. Guo, W.-H. Li, C.-Q. Li, Y.-L. Jin, R.-X. Li and F.-F. Jian, Sci. China: Chem., 2014, 57, 9; (c) Y.-Y. Dong, X. Xu, G.-P. Zhou, H. Miao, G.-H. $\mathrm{Hu}$ and Y. Xu, Dalton Trans., 2015, 44, 18347; (d) H. Miao, Y.-Y. Dong, Z.-W. Chen, X.-X. He, G.-H. Hu and Y. Xu, Dalton Trans., 2016, 45, 12717; (e) G.-H. Hu, H. Miao, H. Mei, S. Zhou and Y. Xu, Dalton Trans., 2016, 45, 7947; $(f)$ J. Zhuang, L.-K. Yan, C.-G. Liu and Z.-M. Su, Eur. J. Inorg. Chem., 2009, 17, 2529.

11 (a) L.-F. Qi, E.-B. Wang, J. Li and Y.-G. Li, J. Solid State Chem., 2009, 182, 2640; (b) M. Wang, W.-L. Sun, H.-J. Pang, H.-Y. Ma, J. Yu, Z.-F. Zhang, Y. Niu and M.-M. Yin, J. Solid State Chem., 2016, 235, 175.

12 (a) P. Ramaswamy, N.-E. Wong, B.-S. Gelfand and G.-K.-H. Shimizu, J. Am. Chem. Soc., 2015, 137, 7640; (b) X. Zhao, C. Mao, X. Bu and P. Feng, Chem. Mater., 2014,
26, 2492; (c) X.-Y. Dong, R. Wang, J.-B. Li, S.-Q. Zang, H.-W. Hou and T.-C. Mak, Chem. Commun., 2013, 49, 10590.

13 (a) K.-D. Kreuer, Chem. Mater., 1996, 8, 610; (b) W. Weppner, K.-D. Kreuer and A. Rabenau, Angew. Chem., Int. Ed., 1982, 122, 208; (c) P. Ramaswamy, N.-E. Wong and G. K.-H. Shimizu, Chem. Soc. Rev., 2014, 43, 5913.

14 P. Ramaswamy, N.-E. Wong and G.-K. Shimizu, Chem. Soc. Rev., 2014, 43, 5913.

15 M. Sadakiyo, T. Yamada and H. Kitagawa, J. Am. Chem. Soc., 2014, 136, 13166.

16 (a) D.-M. Li, Q. Zhang, P. Wang, J.-Y. Wu, Y.-H. Kan, Y.-P. Tian, H.-P. Zhou, J.-X. Yang, X.-T. Tao and M.-H. Jiang, Dalton Trans., 2011, 40, 8170; (b) T. Geethakrishnan and P.-K. Palanisamy, Opt. Commun., 2007, 270, 424; (c) W.-W. Ju, D. Zhang, D.-R. Zhu and Y. Xu, Inorg. Chem., 2012, 51, 13373; (d) Z.-Q. Ji, Y.-J. Li, T.-M. Pritchett, N.-S. Makarov, J.-E. Haley, Z.-J. Li, M. Drobizhev, A. Rebane and W.-F. Sun, Chem.-Eur. J., 2011, 17, 2479. 